\title{
Increased porcine circovirus type 2 replication in porcine leukocytes in vitro and in vivo by concanavalin A stimulation
}

\author{
D.J. Lefebvre *, P. Meerts ${ }^{1}$, S. Costers, G. Misinzo ${ }^{2}$, F. Barbé, \\ K. Van Reeth, H.J. Nauwynck \\ Laboratory of Virology, Faculty of Veterinary Medicine, Ghent University, Salisburylaan 133, 9820 Merelbeke, Belgium
}

Received 12 December 2007; received in revised form 23 April 2008; accepted 5 May 2008

\begin{abstract}
Previously, it was shown that modulation of the immune system enhances porcine circovirus type 2 (PCV2) replication in pigs. In the present study, the effect of the mitogen concanavalin A (ConA) on PCV2 replication was investigated. Since ConA induces T-lymphocyte activation and initiates the production of interferon-gamma (IFN- $\gamma$ ), a cytokine that enhances PCV2 replication in porcine epithelial and monocytic cell lines in vitro, it was examined if the effects observed with ConA were mediated by IFN- $\gamma$. In an in vitro study, ConA but not IFN- $\gamma$ enhanced PCV2 replication in peripheral blood mononuclear cells (PBMC). Up to $2.08 \%$ and $0.96 \%$ of PBMC were antigen positive for PCV2 strains 1121 and Stoon-1010, respectively, and a low virus production was observed. PCV2-infected PBMC were identified as $\mathrm{CD}^{+}(40 \%), \mathrm{CD}^{+}(54 \%)$ and $\mathrm{IgM}^{+}(11 \%)$. In a subsequent in vivo study, caesarean-derived colostrum-deprived piglets were injected with ConA or IFN- $\gamma 12 \mathrm{~h}$ before inoculation and every 3 days for 9 days after inoculation with strain 1121. PCV2 was isolated from inguinal lymph node biopsies from 10 days post-inoculation (dpi) in ConA-treated pigs and from $15 \mathrm{dpi}$ in non-treated and IFN- $\gamma$-treated pigs. ConA increased PCV2 replication levels, but disease was not observed. Half of the ConA-treated and IFN- $\gamma$-treated pigs showed a delayed humoral immune response, but this delay did not result in increased PCV2 replication in these pigs. These experiments demonstrated that ConA enhances PCV2 replication in PBMC in vitro and in lymphoid tissues in vivo.
\end{abstract}

(C) 2008 Elsevier B.V. All rights reserved.

Keywords: Porcine circovirus type 2; Viral replication; Concanavalin A; Interferon-gamma

\section{Introduction}

* Corresponding author. Tel.: +32 92647377; fax: +32 92647495.

E-mail address: david.lefebvre@ugent.be (D.J. Lefebvre).

${ }^{1}$ Present address: Janssen Animal Health, Turnhoutseweg 30, 2340 Beerse, Belgium.

${ }^{2}$ Present address: Department of Veterinary Microbiology and Parasitology, Faculty of Veterinary Medicine, Sokoine University of Agriculture, P.O. Box 3019, Chuo Kikuu, Morogoro, Tanzania.

Porcine circovirus type 2 (PCV2) is a small, nonenveloped, single-stranded DNA virus. It is a member of the family of the Circoviridae and it is widespread in wild and domestic pigs. In pig dense regions, PCV2 infects all conventional pigs after weaning. The majority of these infections are sub-clinical. Under 
certain conditions, PCV2 infection causes postweaning multisystemic wasting syndrome (PMWS), a multifactorial disease that causes severe growth retardation, weight loss and death in weaned piglets (Segales and Domingo, 2002). PMWS is characterized by severe lymphocytic depletion and monocytic infiltration in lymphoid tissues and high amounts of PCV2 are found within these lesions (Segales and Domingo, 2002).

PCV2 lacks its own polymerases and therefore fully depends on cellular enzymes to complete its infectious cycle. Up till now, only 4 different viral proteins have been described in porcine circovirusinfected cells (Mankertz and Hillenbrand, 2002; Liu et al., 2005), which makes PCV2 incapable of actively modifying the immune response of its host in its own favour, as other more complex viruses do (Tortorella et al., 2000). Therefore, specific conditions in the host intensively influence PCV2 replication. Co-infections with other infectious agents such as porcine parvovirus (PPV) (Allan et al., 1999), porcine reproductive and respiratory syndrome virus (PRRSV) (Allan et al., 2000) and Mycoplasma hyopneumoniae (Opriessnig et al., 2004) enhance PCV2 replication and exacerbate the clinical outcome of a PCV2 infection. Injection of immune stimulating drugs such as the soluble protein antigen Keyhole limpet hemocyanin (KLH) in incomplete Freund's adjuvant (Krakowka et al., 2001) and vaccination (Opriessnig et al., 2003) enhance PCV2 replication as well, suggesting that the induction of an immune response might be a key factor in the induction of high levels of PCV2 replication. However, strategies involving immunestimulating drugs or vaccination have not always been successful in enhancing PCV2 replication and PMWS occurrence (Resendes et al., 2004).

PCV2 replication in lymphoid tissues occurs in Blymphocytes, T-lymphocytes, monocytes and macrophages (Sanchez et al., 2004). Recently, it was shown that the plant lectin concanavalin A (ConA) is able to induce PCV2 replication in $\mathrm{CD}^{+}$peripheral blood mononuclear cells (PBMC) that have been inoculated with PCV2 in vitro (Yu et al., 2007). Mitogen stimulation also induces porcine parvovirus (PPV) replication in porcine peripheral blood lymphocytes (Paul et al., 1979) and TT virus replication in human PBMC (Mariscal et al., 2002). PPV and TT virus are also non-enveloped, single-stranded DNA viruses. The mitogen ConA causes predominantly T-lymphocyte proliferation and activation (Mosmann et al., 1986), leading to the production of lymphokines. More specifically, ConA induces production of high concentrations of interferon-gamma (IFN- $\gamma$ ) in vitro (Verfaillie et al., 2001) and in vivo (Miyagi et al., 2004).

Recently, it was shown that interferon-alpha (IFN$\alpha)$ and especially IFN- $\gamma$ are able to enhance PCV2 replication in cell lines in vitro. When administered after PCV2 inoculation, 1000 units of IFN- $\gamma / 10^{6}$ cells increased the number of PCV2-infected cells in epithelial PK-15 and monocytic 3D4/31 cells with $691 \%$ and 423\%, respectively (Meerts et al., 2005b). However, an in vivo study demonstrated that pigs with high IFN- $\gamma$ mRNA expression levels in PBMC are less susceptible to PCV2 replication (Meerts et al., 2005c). Up till now, the effects of ConA and IFN- $\gamma$ on PCV2 replication in vivo are not known.

It is the aim of the present study to determine the effects of ConA and IFN- $\gamma$ on PCV2 replication in PBMC in vitro and to try to set up a model for the reproduction of PMWS using ConA and IFN- $\gamma$ in vivo.

\section{Material and methods}

\subsection{Cells}

PCV negative PK-15 cells were grown in minimal essential medium (MEM) containing Earle's salts (Gibco, Grand Island, USA), supplemented with 5\% foetal bovine serum (FBS), $0.3 \mathrm{mg} \mathrm{ml}^{-1}$ glutamine, $100 \mathrm{U} \mathrm{ml}^{-1}$ penicillin, $0.1 \mathrm{mg} \mathrm{ml}^{-1}$ streptomycin and $0.1 \mathrm{mg} \mathrm{ml}^{-1}$ kanamycin.

PBMC were separated from blood by density centrifugation at $750 \times g$ on Ficoll-Paque ${ }^{\circledR}$ (Amersham Pharmacia Biotech AB, Uppsala, Sweden). These cells were maintained in RPMI 1640 (Gibco) containing $10 \%$ FBS, $0.3 \mathrm{mg} \mathrm{ml}^{-1}$ glutamine, $100 \mathrm{U} \mathrm{ml}^{-1}$ penicillin, $0.1 \mathrm{mg} \mathrm{ml}^{-1}$ streptomycin, $0.1 \mathrm{mg} \mathrm{ml}^{-1}$ kanamycin, $1 \%$ non-essential amino acids $(100 \times$; Gibco) and $1 \%$ sodium pyruvate ( $100 \mathrm{mM}$; Gibco). Cells were maintained at $37{ }^{\circ} \mathrm{C}$ in the presence of $5 \% \mathrm{CO}_{2}$.

\subsection{Viruses}

PCV2 strains 1121 and Stoon-1010 were used in this study. The replication kinetics of these 2 strains 
have been described in PK-15 cells, foetal cardiomyocytes and alveolar macrophages by Meerts et al. (2005a). For in vitro use, 1121 and Stoon-1010 were at a 29th and 19th passage level on PK-15 cells, respectively. For in vivo inoculation, a 4th passage on PK-15 cells of strain 1121 was used.

\subsection{Concanavalin A and recombinant IFN- $\gamma$}

ConA was purchased from Sigma (Heidelberg, Germany). Recombinant IFN- $\gamma$ (rIFN- $\gamma$ ) was purchased from R\&D Systems (Abingdon, UK).

\subsection{Pigs}

Six 9-month-old conventional PCV2 seronegative pigs were used as blood donors for the isolation of PBMC.

Seventeen caesarean-derived colostrum-deprived $(\mathrm{CD} / \mathrm{CD})$ pigs were obtained from 2 Landrace sows and were raised in sterile conditions in individual isolators.

\subsection{In vitro experiments}

\subsubsection{Inoculation and treatment}

After isolation, PBMC were inoculated with a dose of $10^{4.3} \mathrm{TCID}_{50} / 10^{6} \mathrm{PBMC}$ for $1 \mathrm{~h}$ at $37^{\circ} \mathrm{C}$. After inoculation, cells were washed twice, resuspended in fresh medium and seeded in 24-well cell culture plates (Nunc, Roskilde, Denmark) at a concentration of $10^{6}$ PBMC $\mathrm{ml}^{-1}$. Immediately after seeding, ConA or rIFN- $\gamma$ was added at a dose of $5 \mu \mathrm{g} / 10^{6} \mathrm{PBMC}$ or 1000 units $/ 10^{6}$ PBMC, respectively. A dose of $5 \mu \mathrm{g}$ ConA $/ 10^{6}$ PBMC is commonly used to induce proliferation in porcine PBMC (Verfaillie et al., 2001). A dose of 1000 units of rIFN- $\gamma / 10^{6}$ cells was the most efficient dose to increase the number of PCV2-infected cells in PK-15 and 3D4/31 cells (Meerts et al., 2005b). This dose was effective for stimulating PBMC in vitro, because $24 \mathrm{~h}$ after treatment, a fivefold increase in interleukin-12 levels was observed in supernatant fluids of rIFN- $\gamma$-treated PBMC when compared to nontreated PBMC. This was measured with a commercial ELISA for interleukin-12 (R\&D Systems).

PBMC inoculated with PK-15 cell culture medium and treated with ConA or rIFN- $\gamma$ were included as negative controls.

\subsubsection{Fixation and stainings}

At $0,12,24,36,48,72$ and $96 \mathrm{~h}$ post-inoculation (hpi), PBMC and supernatant fluids were collected. Cells were smeared onto glass slides, fixed in methanol at $-20{ }^{\circ} \mathrm{C}$ for $10 \mathrm{~min}$ and stored at $-20{ }^{\circ} \mathrm{C}$ until use. Supernatant fluids were centrifuged at $2900 \times g$ for $10 \mathrm{~min}$ and stored at $-20{ }^{\circ} \mathrm{C}$ until virus titration on PK-15 cells.

Expression kinetics of the non-structural Rep protein and the structural capsid protein were determined with double immunofluorescence stainings using the monoclonal antibody (mAb) F210, directed against the PCV2 Rep protein (McNeilly et al., 2001), and biotinylated purified porcine polyclonal antibodies (pAbs), directed against the PCV2 capsid protein (Meerts et al., 2005a). Briefly, fixed cell smears were air-dried at room temperature for $10 \mathrm{~min}$. Next, they were incubated with an optimal dilution of mAb F210 in phosphate-buffered saline (PBS). Subsequently, a 1:500 dilution of fluorescein isothiocyanate (FITC)-labelled goat anti-mouse pAbs (Molecular Probes, Eugene, USA) in PBS was applied. This was followed by an optimal dilution of biotinylated purified porcine pAbs in PBS, followed by incubation with a 1:100 dilution of Texas Redlabelled streptavidin (Molecular Probes) in PBS. Each of these incubations were performed for $1 \mathrm{~h}$ at $37^{\circ} \mathrm{C}$. Finally, Hoechst 33342 (Molecular Probes) was applied at a concentration of $10 \mu \mathrm{g} \mathrm{ml}^{-1}$ for $10 \mathrm{~min}$ at room temperature, in order to visualize the nucleus. Cell smears were washed three times with PBS between the incubations. Stained cell smears were mounted with a glycerol solution containing 1,4diazabicyclo(2.2.2)octane (DABCO) anti-fading agent (Janssen Chimica, Beerse, Belgium). A LEICA DM/RBE fluorescence microscope (Leica Microsystems $\mathrm{GmbH}$, Heidelberg, Germany) was used for visualization. Expression kinetics of the Rep protein and the capsid protein were assessed at $0,12,24,36$, 48, 72 and $96 \mathrm{hpi}$, by determination of nuclear and cytoplasmic localization of PCV2 antigens in 5000 PBMC at each time point.

PCV2 positive PBMC (strain 1121) were further characterized at 0,36 and 72 hpi by using mAbs directed against cell markers CD4, CD8, IgM and SWC3, respectively. The cell marker CD4 is present on T-helper and memory T-helper lymphocytes, regulatory T-lymphocytes and natural interferon-alpha 
producing cells (Pescovitz et al., 1984; Charley and Lavenant, 1990). CD8 is present on cytotoxic and gamma-delta T-lymphocytes, memory T-lymphocytes and natural killer cells (Pescovitz et al., 1984; Saalmuller et al., 1994). IgM is present on naïve Blymphocytes, B-lymphoblasts and IgM-producing plasma cells (Van Zaane and Hulst, 1987). SWC3 is present on monocytes, macrophages, dendritic cells and granulocytes (Pescovitz et al., 1984; Paillot et al., 2001). The staining procedure was similar to the technique described above. Cell smears were incubated with optimal dilutions of mAbs against CD4, CD8, IgM or SWC3, respectively, followed by FITClabelled goat anti-mouse pAbs. Thereafter, cell smears were stained with biotin-conjugated porcine antiPCV2 pAbs, followed by Texas Red-labelled streptavidin. On each cell smear, all PCV2 positive cells were analyzed by fluorescence microscopy.

\subsubsection{Virus titration of PBMC culture supernatant}

Tenfold dilutions of PBMC culture supernatants were inoculated on semi-confluent monolayers of PCV negative PK-15 cells. After $72 \mathrm{~h}$ of incubation, cells were fixed in $4 \%$ paraformaldehyde in PBS. PCV2-infected cells were detected via an immunoperoxidase monolayer assay (IPMA) as described by Labarque et al. (2000).

\subsubsection{Statistical analysis}

The statistical significance of differences between non-treated PBMC and ConA-treated PBMC and between non-treated PBMC and rIFN- $\gamma$-treated PBMC was tested by applying two-sided KruskalWallis tests. Differences were considered significant when $p<0.05$. Statistical analyses were performed using S-PLUS (S-PLUS 6.1, Insightful Corporation, Seattle, USA, 2002).

\subsection{In vivo experiments}

\subsubsection{Inoculation and treatment}

The set up of the experiment is illustrated in Table 1 . The $17 \mathrm{CD} / \mathrm{CD}$ pigs were randomly divided in 5 groups. At 19 days of age, all pigs from groups A (PCV2/-), B (PCV2/ConA) and C (PCV2/rIFN- $\gamma$ ) were inoculated intraperitoneally and oronasally with a total dose of $10^{4.3}$ TCID $_{50}$ of strain 1121. Pigs of
Table 1

Distribution of caesarean-derived colostrum-deprived pigs in different groups with specific manipulations per group

\begin{tabular}{llllc}
\hline Group & $n$ & PCV2 inoculation & Treatment & Pig numbers \\
\hline A & 4 & Yes & - & $1-4$ \\
B & 4 & Yes & ConA & $5-8$ \\
C & 4 & Yes & rIFN- $\gamma$ & $9-12$ \\
D & 3 & No & ConA & $13-15$ \\
E & 2 & No & rIFN- $\gamma$ & $16-17$ \\
\hline
\end{tabular}

groups D (-/ConA) and $\mathrm{E}(-/ \mathrm{rIFN}-\gamma)$ were mock inoculated with equal volumes of cell culture medium. Treatment regimes with ConA or rIFN- $\gamma$ were designed based on the results of a preliminary experiment in conventional pigs. In PCV2-inoculated PK-15 cells, addition of plasma of a ConA-treated conventional pig or a rIFN- $\gamma$-treated conventional pig increased the number of infected cells with maximum $524 \%$ and $154 \%$, respectively, when compared with plasma samples from the same pigs before ConA or rIFN- $\gamma$ treatment. As a result from this experiment, pigs from groups $\mathrm{B}$ (PCV2/ConA) and D (-/ConA) were injected every 3 days with ConA at a dose of $1.5 \mathrm{mg} \mathrm{kg}^{-1}$ body weight. Half of the dose was injected intramuscularly (IM) in the neck and the other half was injected subcutaneously (SC) in the region of the lower abdomen that is drained by the inguinal lymph nodes. The first injection was administered $12 \mathrm{~h}$ before PCV2 inoculation of the pigs and repeated at 2, 5 and 8 days post-inoculation (dpi). Pigs from groups C (PCV2/rIFN- $\gamma$ ) and E (-/ rIFN- $\gamma$ ) were treated at the same time points with rIFN- $\gamma$ at a dose of 100,000 units ( $3 \mu \mathrm{g}$ of recombinant protein) per treatment: 50,000 units were injected IM in the neck and 50,000 units SC in the lower abdomen. Pigs were monitored for a period of 21 days after PCV2 inoculation and humanly euthanized afterwards, by intravenous injection of a barbiturate overdose (Natriumpentobarbital 20\%, Kela, Hoogstraten, Belgium).

\subsubsection{Clinical monitoring}

Pigs were monitored daily for the appearance of clinical signs that are typically associated with PMWS. These clinical signs include cachexia, depression, respiratory distress and jaundice (Segales and Domingo, 2002). 


\subsubsection{PCV2 replication}

To follow the degree of PCV2 replication in all individual pigs, inguinal lymph node biopsies were collected at different time points as described before (Meerts et al., 2005c). At 10 dpi, a biopsy was taken from the left inguinal lymph node and at $15 \mathrm{dpi}$, a biopsy was taken from the right inguinal lymph node. In order to take lymph node biopsies, the pigs were anaesthetized by IM injection of $2.2 \mathrm{mg}$ tiletamine and $2.2 \mathrm{mg}$ zolazepam (Zoletil $^{\mathbb{R}}$, Virbac, Wavre, Belgium) dissolved in $0.22 \mathrm{ml} 2 \%$ xylazine $\left(\mathrm{XYL}^{\mathrm{M}} \mathrm{M}^{\mathrm{R}}\right.$ $2 \%$, VMD, Arendonk, Belgium) $\mathrm{kg}^{-1}$ body weight. An incision was made in the overlaying skin and half the inguinal lymph node was excised. The wound was closed by mersilene sutures (Mersutures ${ }^{\circledR}$, Ethicon, USA). At the time of euthanasia (21 dpi) the remaining parts of both left and right inguinal lymph nodes were collected.

Ten $\%$ suspensions were made from these biopsies and from the remaining parts of these lymph nodes, and the level of PCV2 replication in these organs was determined by PCV2 titration on PK-15 cells. The detection limit of this technique was $10^{2.7} \mathrm{TCID}_{50} / \mathrm{g}$.

Quantification and immunophenotyping of PCV2 positive cells was performed on inguinal lymph node biopsies that were collected at $15 \mathrm{dpi}$. Serial cryostat sections were fixed in methanol at $-20{ }^{\circ} \mathrm{C}$ for $10 \mathrm{~min}$. Double immunofluorescence stainings for CD4, CD8, IgM or SWC3, respectively, and for PCV2, were performed as described above. Prior to mounting, autofluorescence was quenched by immersion of the sections for $30 \mathrm{~min}$ in a $10 \mathrm{mM}$ dilution of $\mathrm{CuSo}_{4}$ in a $50 \mathrm{mM} \mathrm{NH}_{4}$-acetate buffer at $\mathrm{pH}$ 5.0. PCV2 positive cells were quantified and immunophenotyped using a fluorescence microscope. The total number of PCV2 positive cells and the total number of double positive cells (cell marker and PCV2) were determined over an area of $10 \mathrm{~mm}^{2}$ of tissue.

\subsubsection{Humoral immune response against PCV2}

At $0,7,10,15$ and $21 \mathrm{dpi}$, blood was taken $(1 / 1$ in Alsevers solution) from the jugular vein, in order to monitor total anti-PCV2 $\mathrm{Ab}$ titres by an IPMA described previously (Labarque et al., 2000). PCV2 neutralizing Abs were determined by a sensitive neutralization assay described previously (Meerts et al., 2005c).
The animal experiments described in this study were authorized and supervised by the Ethical and Animal Welfare Committee of the Faculty of Veterinary Medicine of Ghent University.

\subsubsection{Statistical analysis}

The statistical significance of differences between non-treated pigs and ConA-treated pigs and between non-treated pigs and rIFN- $\gamma$-treated pigs was tested by applying two-sided Kruskal-Wallis tests. Differences were considered significant when $p<0.05$. Statistical analyses were performed using S-PLUS (S-PLUS 6.1, Insightful Corporation, Seattle, USA, 2002).

\section{Results}

\subsection{In vitro experiments}

\subsubsection{PCV2 replication kinetics in PBMC}

Fig. 1 demonstrates mean percentages of PCV2 positive cells and antigen expression patterns in PCV2-inoculated PBMC of three conventional PCV2 seronegative pigs (pigs 1, 2 and 3). For strain 1121, maximum numbers of antigen positive cells were very low in non-treated PBMC $(0.06 \%$ in pig 1 at $48 \mathrm{hpi}$, $0.14 \%$ in pig 2 at $72 \mathrm{hpi}$ and $0.04 \%$ in pig 3 at $48 \mathrm{hpi}$ ). Antigen positive cells were observed starting from $36 \mathrm{hpi}$ (pigs 2 and 3) or $48 \mathrm{hpi} \mathrm{(pig} \mathrm{1).} \mathrm{In} \mathrm{ConA-treated}$ PBMC, maximum numbers of antigen positive cells of $2.08 \%, 1.02 \%$ and $2.02 \%$ were observed at $96 \mathrm{hpi}$, 72 hpi and 96 hpi for pigs 1, 2 and 3, respectively. Nuclear localized viral antigens were detected for the first time at 12 hpi for pig 2 and at 36 hpi for pigs 1 and 3. Cytoplasmic localized viral antigens were detected starting from $36 \mathrm{hpi}$. At this time point, $20-50 \%$ of cells with viral antigens in the nucleus showed viral antigens in the cytoplasm and all cells with viral antigens in the cytoplasm showed viral antigens in the nucleus. From 36 to $96 \mathrm{hpi}$, the numbers of total PCV2 antigen positive cells, positive cells with antigens in the nucleus and positive cells with antigens in the cytoplasm were significantly different in ConAtreated PBMC when compared to non-treated PBMC. In rIFN- $\gamma$-treated PBMC, maximum numbers of antigen positive cells were very low $(0.06 \%$ in pig 1 at $72 \mathrm{hpi}, 0.18 \%$ in pig 2 at $72 \mathrm{hpi}$ and $0.06 \%$ in pig 3 at 36 and $48 \mathrm{hpi}$ ). Antigen positive cells were observed 

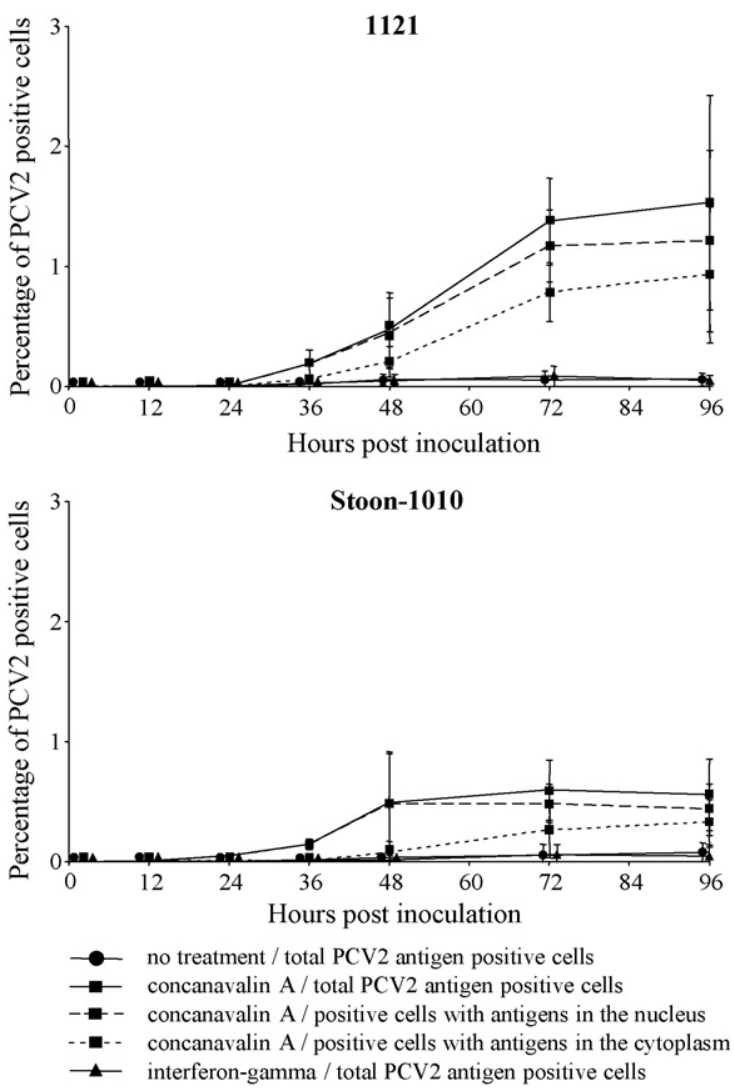

Fig. 1. Mean percentage ( \pm S.D. $)$ of PCV2 antigen positive cells and antigen expression patterns in non-treated, concanavalin A-treated or recombinant interferon-gamma-treated, PCV2-inoculated PBMC of three conventional PCV2 seronegative pigs at different time points after in vitro inoculation of PBMC with strains 1121 and Stoon-1010 (pigs 1, 2 and 3).

starting from 24 hpi (pig 2), 36 hpi (pig 3) or 72 hpi (pig 1).

For Stoon-1010, maximum numbers of antigen positive cells were very low in non-treated PBMC (0.02\% in pig 1 at $96 \mathrm{hpi}, 0.22 \%$ in pig 2 at $96 \mathrm{hpi}$ and $0.00 \%$ in pig 3). Antigen positive cells were observed starting from 12 hpi (pig 2) or 96 hpi (pig 1). In ConAtreated PBMC, maximum numbers of antigen positive cells of $0.96 \%, 0.84 \%$ and $0.34 \%$ were observed at $48 \mathrm{hpi}$ for pig 1 and at $72 \mathrm{hpi}$ for pigs 2 and 3, respectively. Nuclear localized viral antigens were detected for the first time at $24 \mathrm{hpi}$ for pig 1 and at 12 hpi for pigs 2 and 3. Cytoplasmic localized viral antigens were detected for the first time at $24 \mathrm{hpi}$ for pigs 1 and 2 and at 72 hpi for pig 3. At these time points, $12-33 \%$ of cells with viral antigens in the nucleus showed viral antigens in the cytoplasm and all cells with viral antigens in the cytoplasm showed viral antigens in the nucleus. From 24 to $72 \mathrm{hpi}$, the numbers of total PCV2 antigen positive cells and positive cells with antigens in the nucleus were significantly different in ConA-treated PBMC when compared to non-treated PBMC. At $96 \mathrm{hpi}$, the numbers of positive cells with antigens in the cytoplasm were significantly different in ConAtreated PBMC when compared to non-treated PBMC. In rIFN- $\gamma$-treated PBMC, maximum numbers of antigen positive cells were very low $(0.02 \%$ in pig 1 at $36 \mathrm{hpi}, 0.16 \%$ in pig 2 at $72 \mathrm{hpi}$ and $0.02 \%$ in pig 3 at $72 \mathrm{hpi}$ ). Antigen positive cells were observed starting from 12 hpi (pig 2), 36 hpi (pig 1) or 72 hpi (pig 3).

In ConA-treated PBMC, all cells with nuclear localized capsid protein also contained Rep protein in their nucleus. In 89\% (1121) and 81\% (Stoon-1010) of the cells with nuclear localized Rep protein, nuclear localized capsid protein was found. Cells with cytoplasmic staining for capsid protein, without nuclear staining for Rep or capsid proteins, were observed starting from $48 \mathrm{hpi}$ (pigs 2 and 3) or $72 \mathrm{hpi}$ (pig 1) for strain 1121 and starting from $48 \mathrm{hpi}$ (pig 1), 72 hpi (pig 2) or 96 hpi (pig 3) for Stoon-1010. This staining pattern was accompanied with morphological changes typical for cellular degeneration. Rep protein was never detected in the cytoplasm of PCV2 positive cells, except in a small fraction of cells with typical morphological signs of degeneration.

Positive reactions were not observed when staining non-inoculated PBMC for PCV2 antigens or when staining PCV2-inoculated PBMC with an irrelevant isotype-matched $\mathrm{mAb}$ and with porcine PCV2negative control pAbs.

\subsubsection{Identification of $P C V 2$ positive PBMC}

PBMC were obtained from three conventional PCV2 seronegative pigs (pigs 4,5 and 6). The proportions of ConA-treated PCV2 positive PBMC per cell smear, identified as $\mathrm{CD}^{+}, \mathrm{CD}^{+}, \mathrm{IgM}^{+}$or $\mathrm{SWC}^{+}$after inoculation with strain 1121, were determined at 0,36 and 72 hpi. At 0 hpi, PCV2 positive cells were not observed in ConA-treated PBMC. At $36 \mathrm{hpi}$, PCV2 positive cells were identified as $\mathrm{CD}^{+}(48 \pm 5 \%), \mathrm{CD}^{+}(56 \pm 4 \%)$ and $\mathrm{IgM}^{+}$ 
$(12 \pm 3 \%)$. At $72 \mathrm{hpi}, 40 \pm 5 \%$ of PCV2 positive cells were $\mathrm{CD}^{+}, 54 \pm 11 \%$ were $\mathrm{CD}^{+}$and $11 \pm 4 \%$ were $\mathrm{IgM}^{+}$. Viral antigen positive $\mathrm{SWC} 3^{+} \mathrm{PBMC}$ were not found. The numbers of non-treated and rIFN- $\gamma$-treated PCV2 positive PBMC per cell smear were too low for a correct interpretation of results.

\subsubsection{Virus titration of PBMC culture supernatant}

Fig. 2 demonstrates the evolution of mean virus titres in culture supernatants of PCV2-inoculated PBMC of three conventional PCV2 seronegative pigs (pigs 1, 2 and 3). Time-dependent rises in titres were seen for supernatants of ConA-treated PBMC, starting from $72 \mathrm{hpi}$ for strain 1121 and from $48 \mathrm{hpi}$ for Stoon1010. Maximum virus titres of $10^{3.2} \mathrm{TCID}_{50} / \mathrm{ml}$ supernatant and $10^{4.1} \mathrm{TCID}_{50} / \mathrm{ml}$ supernatant were observed for strain 1121 and Stoon-1010 at 96 hpi. Significant differences between virus titres in supernatants of non-treated PBMC and ConA-treated PBMC were observed at 72 and $96 \mathrm{hpi}$ for strain
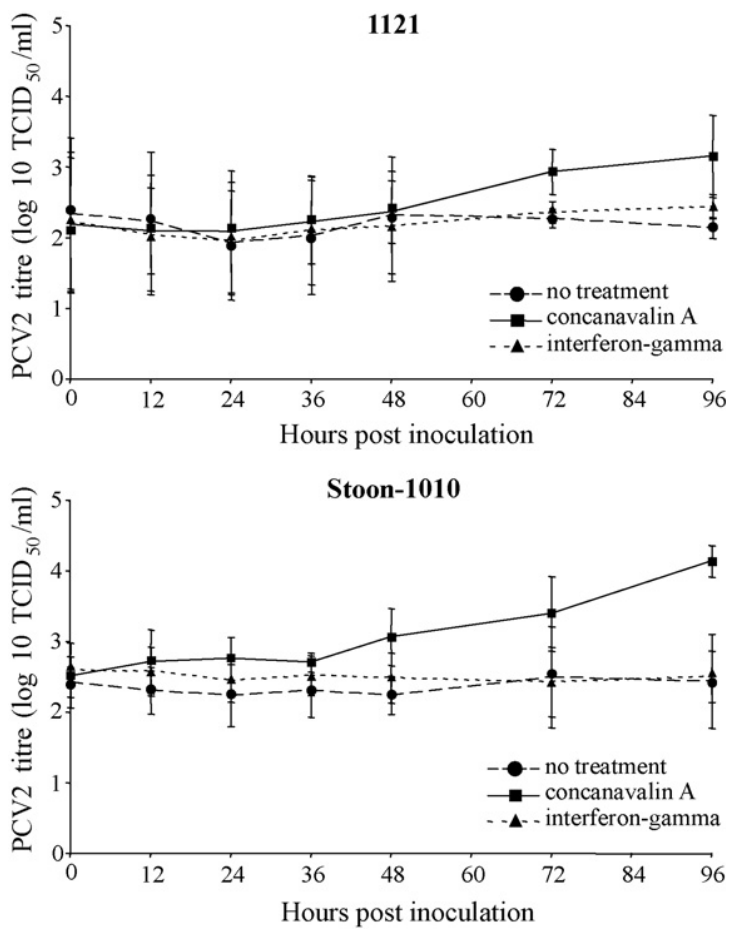

Fig. 2. Evolution of mean $( \pm$ S.D. $)$ PCV2 titres in culture supernatants of non-treated, concanavalin A-treated or recombinant interferon-gamma-treated, PCV2-inoculated PBMC of three conventional PCV2 seronegative pigs (pigs 1, 2 and 3).
1121 and at 36, 48 and $96 \mathrm{hpi}$ for Stoon-1010. A small but statistically significant difference between virus titres in supernatants of non-treated PBMC and rIFN$\gamma$-treated PBMC was observed for strain 1121 at 96 hpi.

\subsection{In vivo experiments}

\subsubsection{Clinical monitoring}

Clinical signs suggestive of PMWS were not observed. Differences in general conditions were not observed between any of the pigs. Inguinal lymph nodes of all pigs of groups B (PCV2/ConA), C (PCV2/ rIFN- $\gamma), \mathrm{D}(-/ \mathrm{ConA})$ and $\mathrm{E}(-/ \mathrm{rIFN}-\gamma)$ were noticeably enlarged and pale. This was observed from the first time a biopsy was taken, up to the end of the study. Enlarged, pale inguinal lymph nodes were not observed in any of the pigs of group A (PCV2inoculated, non-treated pigs). Pig 6 (group B, PCV2/ ConA) died during blood sampling at $15 \mathrm{dpi}$.

\subsubsection{PCV2 replication}

The evolution in PCV2 titres in the inguinal lymph nodes of individual pigs is shown in Fig. 3. From all pigs of groups A, B and C (PCV2-inoculated pigs), PCV2 was isolated at least at one time point. PCV2 could be detected for the first time at $15 \mathrm{dpi}$ in pigs of groups A (PCV2/-) and $\mathrm{C}(\mathrm{PCV} 2 / \mathrm{rIFN}-\gamma)$. In pigs of group $\mathrm{B}$ (PCV2/ConA), PCV2 was already isolated from the lymph node biopsies taken at $10 \mathrm{dpi}$. Titres at this time point ranged between $10^{3.0}$ and $10^{4.3} \mathrm{TCID}_{50} / \mathrm{g}$. At 15 and $21 \mathrm{dpi}, \mathrm{PCV} 2$ titres in pigs of group B (PCV2/ ConA) were generally higher than in pigs of groups $\mathrm{A}$ (PCV2/-) and C (PCV2/rIFN- $\gamma$ ), but due to the high variation in PCV2 titres between pigs in the same groups and due to the limited number of pigs per group, a significant difference between groups $\mathrm{A}(\mathrm{PCV} 2 /-)$ and $\mathrm{B}$ (PCV2/ConA) could only be observed at $10 \mathrm{dpi}$ and not at 15 and $21 \mathrm{dpi}$.

The general evolution in PCV2 titres in time was similar in all pigs from groups A, B and C (PCV2inoculated pigs), except in one pig (pig 7) from group $\mathrm{B}$ (PCV2/ConA). Eleven out of twelve pigs of groups $\mathrm{A}, \mathrm{B}$ and $\mathrm{C}$ (PCV2-inoculated pigs) showed a peak of PCV2 replication at 15 dpi. Afterwards, the PCV2 titres decreased in all these pigs. Pig 7 (group B, PCV2/ConA) showed a gradual increase in PCV2 titre until the end of the study. 


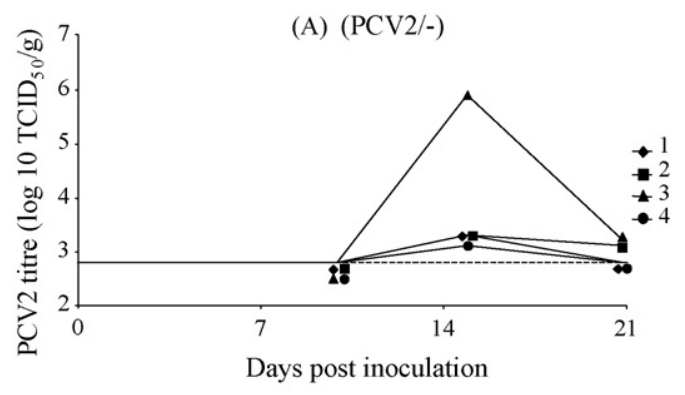

(B) $(\mathrm{PCV} 2 / \mathrm{ConA})$

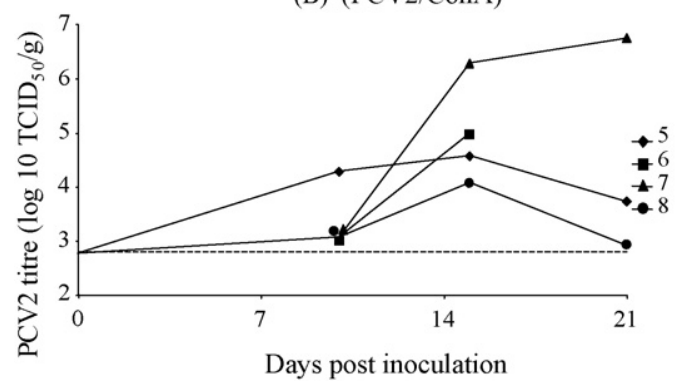

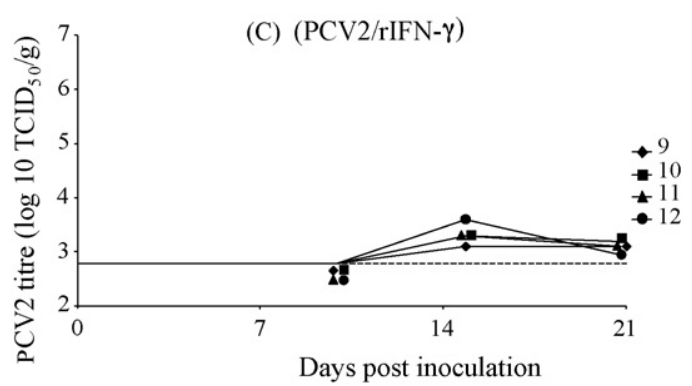

(D) $(-/ \mathrm{ConA})$ and $\mathrm{E}(-/ \mathrm{rIFN}-\gamma)$

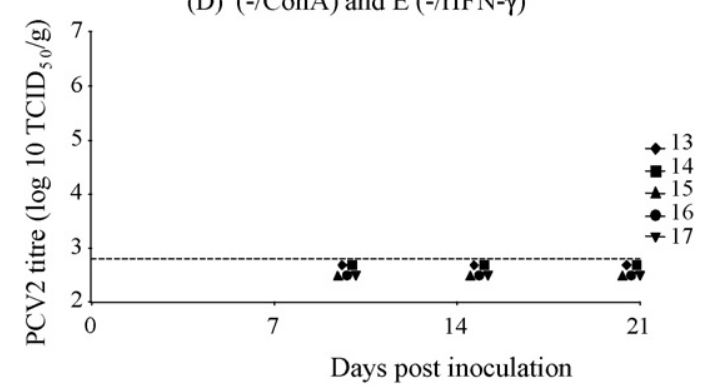

Fig. 3. Evolution of PCV2 titres in inguinal lymph nodes of PCV2-inoculated caesarean-derived colostrum-deprived pigs of groups A (nontreated), B (treated with concanavalin A, ConA) and C (treated with recombinant interferon-gamma, rIFN- $\gamma$ ), and of non-inoculated pigs of groups $\mathrm{D}$ (treated with concanavalin $\mathrm{A}, \mathrm{ConA}$ ) and $\mathrm{E}$ (treated with recombinant interferon-gamma, rIFN- $\gamma$ ). The dashed line represents the detection limit of the assay $\left(10^{2.7} \mathrm{TCID}_{50} / \mathrm{g}\right)$.

In pigs of groups $\mathrm{D}$ and $\mathrm{E}$ (non-inoculated pigs), PCV2 was never isolated during the study.

Table 2 shows the results of the quantification and immunophenotyping of PCV2 positive cells in inguinal lymph node biopsies at $15 \mathrm{dpi}$. In biopsies from pigs of groups A (PCV2/-) and C (PCV2/rIFN$\gamma$ ), low numbers of PCV2 positive cells were observed (less than $20 \mathrm{PCV} 2$ positive cells per $10 \mathrm{~mm}^{2}$ ). In these pigs, PCV2 was mainly localized in $\mathrm{SWC}^{+}$ cells, but in some pigs small proportions of PCV2 positive cells were $\mathrm{CD} 4^{+}, \mathrm{CD}^{+}$or $\mathrm{IgM}^{+}$. PCV2 positive cells were mainly observed as single cells in follicular and parafollicular regions.

The number of PCV2 positive cells was significantly higher in biopsies from group B (PCV2/ConA) pigs 5, 6 and 7 (389-664 PCV2 positive cells per $\left.10 \mathrm{~mm}^{2}\right)$, when compared to pigs from group A (PCV2/-). In pigs 5, 6 and 7, PCV2 was found in $\mathrm{CD}^{+}, \mathrm{CD}^{+}, \mathrm{IgM}^{+}$and $\mathrm{SWC}^{+}$cells. In pigs 6 and 7 , $\mathrm{SWC}^{+}$cells were the predominantly PCV2 positive cell type (75\% and $66 \%$, respectively). In pig 5, the percentages of $\mathrm{CD}^{+}, \mathrm{CD}^{+}, \mathrm{IgM}^{+}$and $\mathrm{SWC}^{+} \mathrm{PCV} 2$ positive cells ranged from $14 \%$ to $33 \%$. In pigs 5, 6 and 7 , the vast majority of PCV2 positive cells were located in the peripheral areas of the follicular regions and in the parafollicular regions. In these pigs, PCV2 antigens were occasionally $(<5 \%)$ observed in the nucleus of $\mathrm{CD}^{+}, \mathrm{CD}^{+}, \mathrm{IgM}^{+}$and $\mathrm{SWC}^{+}$cells. For pig 8 (group $\mathrm{B}, \mathrm{PCV} 2 / \mathrm{ConA})$, similar observations were made as for pigs from groups $\mathrm{A}$ (PCV2/-) and C (PCV2/rIFN- $\gamma$ ).

PCV2 positive cells were not observed in any of the pigs of groups $\mathrm{D}$ and $\mathrm{E}$ (non-inoculated pigs).

\subsubsection{Humoral immune response against PCV2}

The evolution in PCV2-specific Abs, as demonstrated by IPMA, is shown in Fig. 4. Anti-PCV2 Abs were demonstrated in all pigs from groups A, B and $\mathrm{C}$ (PCV2-inoculated pigs), except in the pig that died at $15 \mathrm{dpi}$ (pig 6, group B, PCV2/ConA). Differences were observed in the time points at which anti-PCV2 Abs were detected for the first time. Pigs from group A (PCV2/-) seroconverted at 10 or $15 \mathrm{dpi}$. In groups $\mathrm{B}$ (PCV2/ConA) and C 
Table 2

Quantification and immunophenotyping of PCV2 positive cells at 15 days post-inoculation in inguinal lymph node biopsies of PCV2-inoculated caesarean-derived colostrum-deprived pigs of groups A (non-treated), B (treated with concanavalin A, ConA) and C (treated with recombinant interferon-gamma, rIFN- $\gamma$ )

\begin{tabular}{|c|c|c|c|c|c|c|c|}
\hline \multirow[t]{2}{*}{ Group } & \multirow[t]{2}{*}{ Pig no. } & \multirow[t]{2}{*}{ Treatment } & \multirow{2}{*}{$\begin{array}{l}\text { Virus titre } \\
\left(\log 10 \mathrm{TCID}_{50} / \mathrm{g}\right)\end{array}$} & \multicolumn{4}{|c|}{ Identification of PCV2 positive cells as ${ }^{\mathrm{a}}$} \\
\hline & & & & $\overline{\mathrm{CD}} 4^{+}$ & $\mathrm{CD}^{+}$ & $\operatorname{IgM}^{+}$ & $\mathrm{SWC}^{+}$ \\
\hline \multirow[t]{4}{*}{ A } & 1 & - & 3.3 & $2 / 9(22 \%)$ & $1 / 5(20 \%)$ & $1 / 5(20 \%)$ & $5 / 7(71 \%)$ \\
\hline & 2 & - & 3.3 & $0 / 4(0 \%)$ & $0 / 10(0 \%)$ & $0 / 2(0 \%)$ & $1 / 1(100 \%)$ \\
\hline & 3 & - & 5.8 & $4 / 18(22 \%)$ & $0 / 13(0 \%)$ & $3 / 10(30 \%)$ & $7 / 11(64 \%)$ \\
\hline & 4 & - & 3.0 & $0 / 2(0 \%)$ & $0 / 2(0 \%)$ & $0 / 4(0 \%)$ & $1 / 1(100 \%)$ \\
\hline \multirow[t]{4}{*}{ B } & 5 & ConA & 4.5 & $140 / 434(32 \%)$ & $60 / 432(14 \%)$ & $89 / 389(23 \%)$ & $136 / 418(33 \%)$ \\
\hline & 6 & ConA & 5.0 & $77 / 635(12 \%)$ & $69 / 664(10 \%)$ & $70 / 555(13 \%)$ & $339 / 454(75 \%)$ \\
\hline & 7 & ConA & 6.3 & $72 / 570(13 \%)$ & $84 / 555(15 \%)$ & $44 / 537(8 \%)$ & $394 / 601(66 \%)$ \\
\hline & 8 & ConA & 4.0 & $0 / 4(0 \%)$ & $0 / 5(0 \%)$ & $0 / 1(0 \%)$ & 4/4 (100\%) \\
\hline \multirow[t]{4}{*}{$\mathrm{C}$} & 9 & $\mathrm{rIFN}-\gamma$ & 3.0 & $1 / 8(13 \%)$ & $0 / 4(0 \%)$ & $0 / 7(0 \%)$ & $12 / 16(75 \%)$ \\
\hline & 10 & rIFN- $\gamma$ & 3.3 & $0 / 2(0 \%)$ & $0 / 1(0 \%)$ & $0 / 2(0 \%)$ & $1 / 2(50 \%)$ \\
\hline & 11 & rIFN- $\gamma$ & 3.3 & $0 / 1(0 \%)$ & $0 / 2(0 \%)$ & $0 / 1(0 \%)$ & $2 / 2(100 \%)$ \\
\hline & 12 & rIFN- $\gamma$ & 3.5 & $1 / 10(10 \%)$ & $1 / 2(50 \%)$ & $0 / 6(0 \%)$ & $10 / 15(67 \%)$ \\
\hline
\end{tabular}

Pigs from groups D and E (non-inoculated pigs) did not have PCV2 positive cells.

${ }^{\text {a }}$ Number of both PCV2 and cell marker positive cells/total number of PCV2 positive cells per $10 \mathrm{~mm}^{2}$ tissue.

(PCV2/rIFN- $\gamma$ ), only 2 out of 4 pigs seroconverted at $15 \mathrm{dpi}$. In the other pigs of groups $\mathrm{B}$ (PCV2/ ConA) and $\mathrm{C}$ (PCV2/rIFN- $\gamma$ ), seroconversion against the virus was delayed until 21 dpi. Statistically significant differences were not detected at any of the time points. PCV2 neutralizing Abs evolved in a similar way as PCV2-specific Abs detected by IPMA (data not shown). None of the pigs from groups $\mathrm{D}$ or $\mathrm{E}$ (non-inoculated pigs) seroconverted against PCV2.
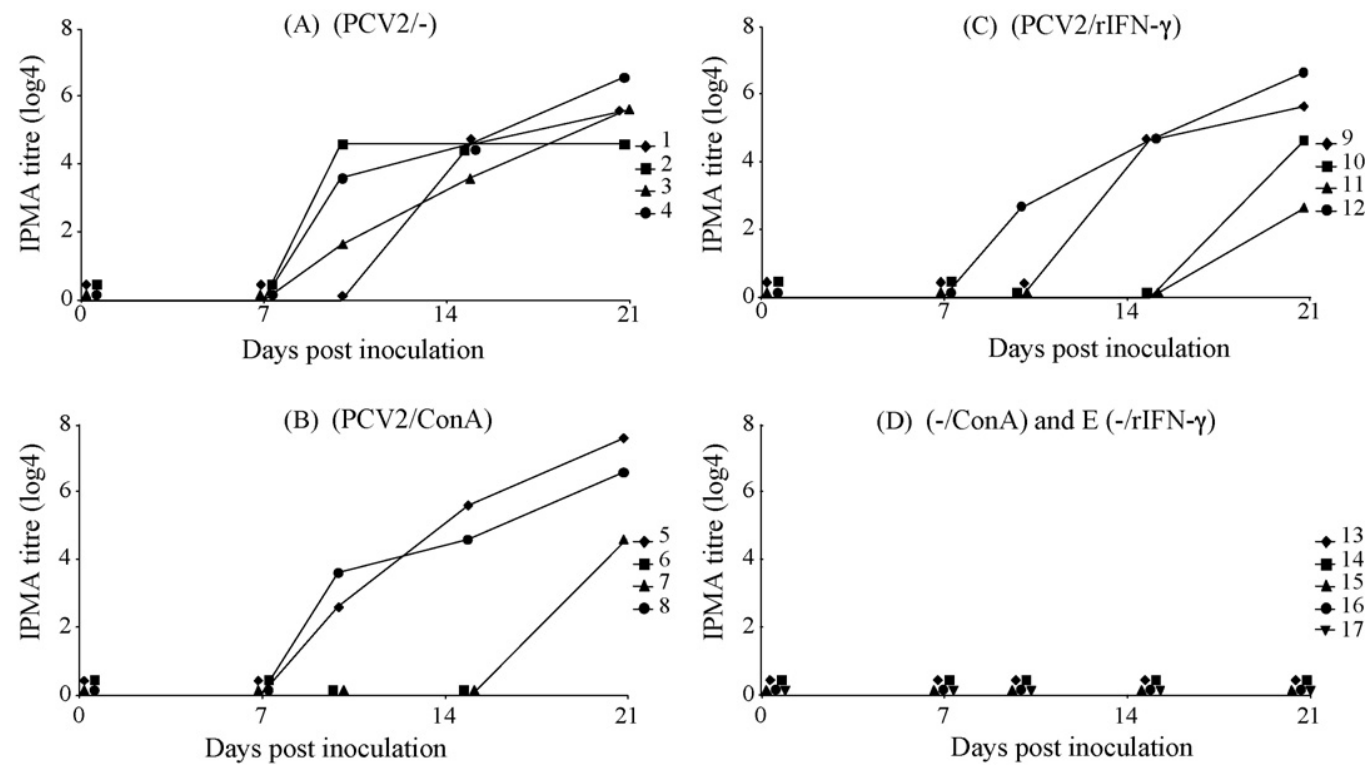

Fig. 4. Evolution of anti-PCV2 antibody titres (IPMA) in PCV2-inoculated caesarean-derived colostrum-deprived pigs of groups A (nontreated), B (treated with concanavalin A, ConA) and C (treated with recombinant interferon-gamma, rIFN- $\gamma$ ), and in non-inoculated pigs of groups D (treated with concanavalin A, ConA) and $\mathrm{E}$ (treated with recombinant interferon-gamma, rIFN- $\gamma$ ). 


\section{Discussion}

In the present study, it was shown that the mitogen ConA increases PCV2 replication in porcine leukocytes both in vitro and in vivo. An effect of rIFN- $\gamma$ on PCV2 replication in leukocytes was not observed under the conditions of the present study. Expression of PCV2 antigens in ConA-stimulated PBMC was observed starting from 12 to $36 \mathrm{hpi}$, depending on the PCV2 strain and the blood donor that were used. This is in agreement with another study, in which PCV2 replication was observed in ConA-stimulated PBMC from 18 hpi onwards (Yu et al., 2007). In the present study, the first detectable viral antigens were localized in the nucleus. These antigens were identified as Rep proteins and capsid proteins. This suggests that in the early stages of infection, newly synthesized Rep and capsid proteins are efficiently transported to the nucleus where genome replication and encapsidation take place. As infection progressed, the number of cells with capsid proteins in the cytoplasm increased, suggesting the translocation of assembled virions from the nucleus to the cytoplasm, as suggested previously by Finsterbusch et al. (2005). At the late stages of infection, cells with intense cytoplasmic staining but without nuclear staining were observed. This was accompanied with morphological changes typical for cellular degeneration, suggesting that PCV2 infection may lead to cell death. Only in these degenerated cells, the Rep protein was occasionally found in the cytoplasm, indicating a very strong affinity of the Rep protein for the nucleus in viable cells. The results further suggest that the rise in PCV2 titres in culture supernatants coincided with the appearance of these degenerated cells. The fact that PCV2 antigens were most frequently found in the nucleus of PBMC early in replication contradicts with earlier findings in PK-15 cells. The majority of PCV2-infected PK-15 cells have capsid antigens in the cytoplasm without having Rep or capsid antigens in the nucleus during the early stages of the replication cycle (Meerts et al., 2005a). Since it is known that cellular transcription factors of lymphoid and epithelial cell types can have different specificities for promoters, enhancers and co-activators (Foster et al., 1985; Forsberg and Westin, 1991), it can be speculated that in PK-15 cells the RNA polymerase II transcription-initiation complex might have a higher affinity for the promoter region of the capsid gene than for the promoter region of the Rep gene, leading to expression of the capsid protein in a large number of cells without expression of the Rep protein. In ConA-treated PBMC, the affinities of this complex for both promoters may be equal, leading to a simultaneous expression of the Rep protein and the capsid protein.

In the present study, it was demonstrated that PCV2 replicates in $\mathrm{CD}^{+}, \mathrm{CD}^{+}$and $\mathrm{IgM}^{+} \mathrm{PBMC}$, suggesting that not only circulating T-lymphocytes, which was demonstrated previously by Yu et al. (2007), but also circulating B-lymphocytes may be susceptible to $\mathrm{PCV} 2$ replication in vitro. Since CD4 is also present on e.g. natural IFN- $\alpha$ producing cells (Charley and Lavenant, 1990) and since CD8 is also present on e.g. natural killer cells (Saalmuller et al., 1994), we cannot exclude the possibility that in vitro stimulation with ConA makes these cell types susceptible to PCV2 replication as well. Further research should clarify this issue. As in other in vitro studies (Yu et al., 2007), we failed to demonstrate PCV2 replication in PBMCderived monocytes.

Meerts et al. (2005b) have previously shown that IFN- $\gamma$ enhances PCV2 replication in vitro in porcine epithelial and monocytic cell lines. This enhancing effect by IFN- $\gamma$ was caused by an increased internalization of bound virions into the cell. The influence of IFN- $\gamma$ on the internalization of PCV2 in PBMC was not investigated in the present study. In cell lines, active cellular polymerases allow PCV2 to complete its infectious cycle. Therefore, we assume that the enhancing effect of ConA on PCV2 replication in PBMC in vitro was merely due to its high mitotic activity. We assume that the lack of high mitotic activity of rIFN- $\gamma$, under the conditions of the present study, was the main reason why rIFN- $\gamma$ did not have an effect on PCV2 replication in PBMC in vitro.

In preliminary experiments, PCV2 replication was also observed in PBMC stimulated with phytohaemagglutinin and a combination of ionomycin and phorbol dibutyrate but not with LPS (data not shown). The best results were obtained with ConA and therefore this mitogen was selected for the present study. The technique that has been described is inexpensive, easy to perform and therefore it is potentially suitable for detailed in vitro studies of the PCV2 replication cycle in lymphocytes, studies that are nowadays merely performed in cell lines. 
In the present study, it was shown that treatment of $\mathrm{CD} / \mathrm{CD}$ pigs with ConA renders them more susceptible to an increased PCV2 replication. Injecting the pigs with rIFN- $\gamma$, following the protocol that was used in the present study, could not induce this increased PCV2 replication. The different outcomes of the ConA and rIFN- $\gamma$ treatments could be due to various mechanisms. ConA is known to cause proliferation and activation of mainly T-lymphocytes (Mosmann et al., 1986), but it also affects other immune cell types such as Blymphocytes (Andersson et al., 1972) and monocytes/ macrophages (Smith and Goldman, 1972). ConA also induces various cytokines and IFN- $\gamma$ is just one of them. ConA thus has a much wider range of biological activities than IFN- $\gamma$. ConA also induces much higher concentrations and a more prolonged production of IFN- $\gamma$ in animals compared to the IFN- $\gamma$ concentration that can be reached by injecting rIFN- $\gamma$. Injected rIFN- $\gamma$ is very quickly removed from the body (Lortat-Jacob et al., 1996), while ConA induces a continuous production of IFN- $\gamma$ by the T-lymphocytes of the animal. Unfortunately, we were not able to demonstrate the presence of IFN- $\gamma$ in plasma samples of the $\mathrm{CD} / \mathrm{CD}$ pigs of the present study, nor with a bio-assay on PK-15 cells, nor with a commercial ELISA for IFN- $\gamma$ (Biosource Europe, Nivelles, Belgium), indicating that IFN- $\gamma$ blood levels were very low at the times of blood sampling (data not shown). Nevertheless, the treatments of pigs with ConA or rIFN- $\gamma$ were effective since inguinal lymph nodes of treated pigs were clearly enlarged, whether these pigs were inoculated with PCV2 or not. Therefore, results from the present study are indicative that the enhancing effect of ConA treatment on PCV2 replication was due to the global effect of ConA on the pig's immune system and not to the effect of IFN- $\gamma$ alone. Obviously, more research needs to be performed to address this issue.

A remarkable difference between ConA-treated pigs and non-treated and rIFN- $\gamma$-treated pigs was observed in inguinal lymph node biopsies collected at 15 dpi. High numbers of PCV2-infected cells were observed in 3 out of 4 ConA-treated pigs. PCV2infected cells were identified as $\mathrm{CD}^{+}, \mathrm{CD}^{+}, \mathrm{IgM}^{+}$ and $\mathrm{SWC}^{+}$, as demonstrated previously by Sanchez et al. (2004). Although PCV2 replicated to high levels in cells of the immune system, only 2 of these 3 pigs showed a delayed onset of the humoral immune response against PCV2. High levels of PCV2 replication in cells of the immune system were not observed in non-treated and rIFN- $\gamma$-treated pigs. Still, a delayed onset of the humoral immune response was observed in 2 out of 4 rIFN- $\gamma$-injected pigs. This suggests that the delayed humoral immune response observed in 2 out of 4 ConA-treated and in 2 out of 4 rIFN- $\gamma$-treated pigs was not caused by high levels of PCV2 replication in cells of the immune system, but might have been caused by a common effect of ConA and rIFN- $\gamma$ treatments in these specific pigs. Possible responsible mechanisms include the inhibitory effects of ConA-activated suppressor T-cells on B-cell proliferation and antibody production (Redelman et al., 1976), and the inhibitory effect of IFN- $\gamma$ on the early stages of B-cell activation (Abed et al., 1994). The present results further suggest that an impaired humoral immune response against PCV2 is not sufficient to cause high levels of PCV2 replication. Further research should deal with these issues.

In the present study, it was again demonstrated that it can be difficult to reproduce PCV2-associated disease in $\mathrm{CD} / \mathrm{CD}$ pigs. Even in the ConA-treated pigs that experienced an increased PCV2 replication, clinical signs were not observed. Still, the ConA treatment might provide a valuable tool to investigate the link between high PCV2 replication and PMWS. Several treatments of $\mathrm{CD} / \mathrm{CD}$ pigs that influence the pig's immune system have been described until now. It has been demonstrated that immune stimulation (Krakowka et al., 2001), immune suppression by Cyclosporin A (Meerts et al., 2005c) and mitogen treatment (the present study) are able to increase PCV2 replication in pigs. This observation may indicate that there is an unstable equilibrium between a specific immune response that is able to neutralize PCV2 and to eliminate PCV2-infected cells, and an immune response that facilitates the replication of the virus in the pig. This fragile balance might be the underlying mechanism responsible for the high variation that is observed in PCV2 replication and clinical outcome between individual pigs and the even higher variation between different studies.

\section{Acknowledgements}

The authors acknowledge Dr. G. Allan and Dr. F. McNeilly from Queen's University Belfast for 
providing $\mathrm{mAb}$ F210. The authors thank M. Bauwens, C. Boone and C. Bracke for their excellent technical assistance during the laboratory analysis of the samples. F. De Backer, G. Opsomer and Dr. S. Van Gucht are acknowledged for their helpful assistance during surgery. This research was partially funded by the Belgian Federal Public Service for Health, Food Chain Safety and Environment. D.J. Lefebvre receives a 'Dehousse'-grant from Ghent University. This grant is funded by the EU (Sixth Framework Programme, Project No. 513928, coordinated by Dr. Gordon Allan).

\section{References}

Abed, N.S., Chace, J.H., Cowdery, J.S., 1994. T cell-independent and $\mathrm{T}$ cell-dependent $\mathrm{B}$ cell activation increases IFN-gamma $\mathrm{R}$ expression and renders $B$ cells sensitive to IFN-gammamediated inhibition. J. Immunol. 153, 3369-3377.

Allan, G.M., Kennedy, S., McNeilly, F., Foster, J.C., Ellis, J.A., Krakowka, S.J., Meehan, B.M., Adair, B.M., 1999. Experimental reproduction of severe wasting disease by co-infection of pigs with porcine circovirus and porcine parvovirus. J. Comp. Pathol. $121,1-11$.

Allan, G.M., McNeilly, F., Ellis, J., Krakowka, S., Meehan, B., McNair, I., Walker, I., Kennedy, S., 2000. Experimental infection of colostrum deprived piglets with porcine circovirus 2 (PCV2) and porcine reproductive and respiratory syndrome virus (PRRSV) potentiates PCV2 replication. Arch. Virol. 145, 2421-2429.

Andersson, J., Edelman, G.M., Moller, G., Sjoberg, O., 1972. Activation of B lymphocytes by locally concentrated concanavalin A. Eur. J. Immunol. 2, 233-235.

Charley, B., Lavenant, L., 1990. Characterization of blood mononuclear cells producing IFN alpha following induction by coronavirus-infected cells (porcine transmissible gastroenteritis virus). Res. Immunol. 141, 141-151.

Finsterbusch, T., Steinfeldt, T., Caliskan, R., Mankertz, A., 2005. Analysis of the subcellular localization of the proteins Rep, Rep' and Cap of porcine circovirus type 1. Virology 343, 36-46 Erratum in: Virology (2006) 349, 492.

Forsberg, M., Westin, G., 1991. Enhancer activation by a single type of transcription factor shows cell type dependence. EMBO J. 10, 2543-2551.

Foster, J., Stafford, J., Queen, C., 1985. An immunoglobulin promoter displays cell-type specificity independently of the enhancer. Nature 315, 423-425.

Krakowka, S., Ellis, J.A., McNeilly, F., Ringler, S., Rings, D.M., Allan, G., 2001. Activation of the immune system is the pivotal event in the production of wasting disease in pigs infected with porcine circovirus-2 (PCV-2). Vet. Pathol. 38, 31-42.

Labarque, G.G., Nauwynck, H.J., Mesu, A.P., Pensaert, M.B., 2000. Seroprevalence of porcine circovirus types 1 and 2 in the Belgian pig population. Vet. Quart. 22, 234-236.
Liu, J., Chen, I., Kwang, J., 2005. Characterization of a previously unidentified viral protein in porcine circovirus type 2-infected cells and its role in virus-induced apoptosis. J. Virol. 79, 82628274.

Lortat-Jacob, H., Baltzer, F., Grimaud, J.A., 1996. Heparin decreases the blood clearance of interferon-gamma and increases its activity by limiting the processing of its carboxyl-terminal sequence. J. Biol. Chem. 271, 16139-16143.

Mankertz, A., Hillenbrand, B., 2002. Analysis of transcription of porcine circovirus type 1. J. Gen. Virol. 83, 2743-2751.

Mariscal, L.F., Lopez-Alcorocho, J.M., Rodriguez-Inigo, E., OrtizMovilla, N., de Lucas, S., Bartolomé, J., Carreno, V., 2002. TT virus replicates in stimulated but not in nonstimulated peripheral blood mononuclear cells. Virology 30, 121-129.

McNeilly, F., McNair, I., Mackie, D.P., Meehan, B.M., Kennedy, S., Moffett, D., Ellis, J., Krakowka, S., Allan, G.M., 2001. Production, characterization and applications of monoclonal antibodies to porcine circovirus 2. Arch. Virol. 146, 909-922.

Meerts, P., Misinzo, G., McNeilly, F., Nauwynck, H.J., 2005a. Replication kinetics of different porcine circovirus 2 strains in PK-15 cells, foetal cardiomyocytes and macrophages. Arch. Virol. 150, 427-441.

Meerts, P., Misinzo, G., Nauwynck, H.J., 2005b. Enhancement of porcine circovirus 2 replication in porcine cell lines by IFNgamma before and after treatment and by IFN-alpha after treatment. J. Interf. Cytok. Res. 25, 684-693.

Meerts, P., Van Gucht, S., Cox, E., Vandebosch, A., Nauwynck, H.J., 2005 c. Correlation between type of adaptive immune response against porcine circovirus type 2 and level of virus replication. Viral Immunol. 18, 333-341.

Miyagi, T., Takehara, T., Tatsumi, T., Suzuki, T., Jinushi, M., Kanazawa, Y., Hiramatsu, N., Kanto, T., Tsuji, S., Hori, M., Hayashi, N., 2004. Concanavalin a injection activates intrahepatic innate immune cells to provoke an antitumor effect in murine liver. Hepatology 40, 1190-1196.

Mosmann, T.R., Cherwinski, H., Bond, M.W., Giedlin, M.A., Coffman, R.L., 1986. Two types of murine helper T cell clone. I. Definition according to profiles of lymphokine activities and secreted proteins. J. Immunol. 136, 2348-2357.

Opriessnig, T., Yu, S., Gallup, J.M., Evans, R.B., Fenaux, M., Pallares, F., Thacker, E.L., Brockus, C.W., Ackermann, M.R., Thomas, P., Meng, X.J., Halbur, P.G., 2003. Effect of vaccination with selective bacterins on conventional pigs infected with type 2 porcine circovirus. Vet. Pathol. 40, 521-529.

Opriessnig, T., Thacker, E.L., Yu, S., Fenaux, M., Meng, X.J., Halbur, P.G., 2004. Experimental reproduction of postweaning multisystemic wasting syndrome in pigs by dual infection with Mycoplasma hyopneumoniae and porcine circovirus type 2 . Vet. Pathol. 41, 624-640.

Paillot, R., Laval, F., Audonnet, J.C., Andreoni, C., Juillard, V., 2001. Functional and phenotypic characterization of distinct porcine dendritic cells derived from peripheral blood monocytes. Immunology 102, 396-404.

Paul, P.S., Mengeling, W.L., Brown Jr., T.T., 1979. Replication of porcine parvovirus in peripheral blood lymphocytes, monocytes, and peritoneal macrophages. Infect. Immun. 25, 10031007. 
Pescovitz, M.D., Lunney, J.K., Sachs, D.H., 1984. Preparation and characterization of monoclonal antibodies reactive with porcine PBL. J. Immunol. 133, 368-375.

Redelman, D., Scott, C.B., Sheppard Jr., H.W., Sell, S., 1976. In vitro studies of the rabbit immune system. V. Suppressor T cells activated by concanavalin A block the proliferation, not the induction of antierythrocyte plaque-forming cells. J. Exp. Med. 143, 919-936.

Resendes, A., Segales, J., Balasch, M., Calsamiglia, M., Sibila, M., Ellerbrok, H., Mateu, E., Plana-Duran, J., Mankertz, A., Domingo, M., 2004. Lack of an effect of a commercial vaccine adjuvant on the development of postweaning multisystemic wasting syndrome (PMWS) in porcine circovirus type 2 (PCV2) experimentally infected conventional pigs. Vet. Res. $35,83-90$.

Saalmuller, A., Hirt, W., Maurer, S., Weiland, E., 1994. Discrimination between two subsets of porcine CD8+ cytolytic T lymphocytes by the expression of CD5 antigen. Immunology 81, 578583.

Sanchez Jr., R.E., Meerts, P., Nauwynck, H.J., Ellis, J.A., Pensaert, M.B., 2004. Characteristics of porcine circovirus- 2 replication in lymphoid organs of pigs inoculated in late gestation or post- natally and possible relation to clinical and pathological outcome of infection. J. Vet. Diagn. Invest. 16, 175-185.

Segales, J., Domingo, M., 2002. Postweaning multisystemic wasting syndrome (PMWS) in pigs. A review. Vet. Quart. 24, 109124.

Smith, C.W., Goldman, A.S., 1972. Effects of concanavalin A and pokeweed mitogen in vivo on mouse peritoneal macrophages. Exp. Cell Res. 73, 394-398.

Tortorella, D., Gewurz, B.E., Furman, M.H., Schust, D.J., Ploegh, H.L., 2000. Viral subversion of the immune system. Annu. Rev. Immunol. 18, 861-926.

Van Zaane, D., Hulst, M.M., 1987. Monoclonal antibodies against porcine immunoglobulin isotypes. Vet. Immunol. Immunopathol. 16, 23-26.

Verfaillie, T., Cox, E., To, L.T., Vanrompay, D., Bouchaut, H., Buys, N., Goddeeris, B.M., 2001. Comparative analysis of porcine cytokine production by mRNA and protein detection. Vet. Immunol. Immunopathol. 81, 97-112.

Yu, S., Vincent, A., Opriessnig, T., Carpenter, S., Kitikoon, P., Halbur, P.G., Thacker, E., 2007. Quantification of PCV2 capsid transcript in peripheral blood mononuclear cells (PBMCs) in vitro. Vet. Microbiol. 123, 34-42. 